\title{
Referral Pattern of Patients to Pediatric Neurosciences Department: A Tertiary Care Hospital Study in Bangladesh
}

Dr. Shaoli Sarker ${ }^{1 *}$, Prof. Mustafa Mahbub ${ }^{2}$

\author{
${ }^{1}$ Assistant Professor, Department of Pediatric Neurosciences, Bangladesh Institute of Child Health, Dhaka Shishu (Children) Hospital, \\ Dhaka, Bangladesh \\ ${ }^{2}$ Professor, Department of Pediatric Neurosciences, Bangladesh Institute of Child Health, Dhaka Shishu (Children) Hospital, Dhaka, \\ Bangladesh
}

DOI: $10.36347 /$ sjams.2022.v10i01.005

| Received: 27.11.2021 | Accepted: 03.01.2022 | Published: 10.01.2022

*Corresponding author: Dr. Shaoli Sarker

Assistant Professor, Department of Pediatric Neurosciences, Bangladesh Institute of Child Health, Dhaka Shishu (Children) Hospital, Dhaka, Bangladesh

ORCID: https://orcid.org/0000-0002-1150-7187

\section{Abstract}

Introduction: Referral system is an important part for providing good quality holistic management in child care. A good number of paediatric patients ranging in age from newborn to 18 years old, have been recorded in neurology outpatient and inpatient settings. Several departments might have child patients who need certain specialist care on neurological disorders who are referred by specialists of other disciplines to pediatrics neurology department for specified diagnosis \& proper management, since they excel in such cases. Aim of the study: The aim of this study was to track how patients from other specialties of paediatrics get referred to the specialists of pediatric neurosciences department. Materials \& Methodology: We conducted this prospective study of recruiting 365 children who were referred to Pediatric Neurosciences Department of Dhaka Shishu Hospital by other physicians. Ethical clearance was taken from concerned authority. The data were analyzed using simple proportion, rates and tables and was presented as frequency by using MS-Excel \& SPSS version 20.0. Results: From the total 365 patients, the majority of the 288(78.9\%) referred patients came from the general paediatrics OPD of various hospitals and private practices. Among the remainder, 49(13.42\%) were from paediatric orthopedic OPD, 13(3.56\%) from ophthalmology OPD 7(1.91\%) from ophthalmology IPD, 7(1.91\%) from neurosurgery OPD and $1(0.3 \%)$ from neurosurgery IPD. On the other hand, according to frequency of diagnosis, 88(24.11\%) Epilepsy, 64(17.53\%) Autism spectrum disorder, 41(11.23\%) Neuromuscular disease, 39(10.68\%) Neurometabolic disorder, 27(7.4\%) Cerebral palsy, 30(8.22\%) Syndromic child with ID, 27(7.4\%) Cerebral palsy, 17(4.66\%) Somatoform disorder, 13(3.56\%) Constitutional speech delay \& finally $2(0.55 \%)$ Peripheral neuropathy had been found in this study. Conclusion: The most common cause for referral was to seek advice and management from a special multidisciplinary service. For the majority of their referred patients, a specialist from a department wants a collaborative connection with specialists of other departments. Physicians who get clinical competency training may be most beneficial for referred conditions.

Keywords: Referred patients, Pediatric neurological illness.

Copyright $(2022$ The Author(s): This is an open-access article distributed under the terms of the Creative Commons Attribution 4.0 International License (CC BY-NC 4.0) which permits unrestricted use, distribution, and reproduction in any medium for non-commercial use provided the original author and source are credited.

\section{INTRODUCTION}

In a tertiary specialized hospital, pediatric neuroscience department deals with the diagnosis and management of neurological conditions in neonates (newborns), infants, children, and adolescents referred to a specialized branch of medicine. In neurology inpatients and outpatients, significant proportion of psychiatric illnesses has been reported. A large number of children, ranging in age from newborn to 18 years old, have been recorded in neurology outpatient and inpatient settings [1]. Pediatric neurologists treat children of all ages with comprehensive neurologic treatment age ranging newborns to age 18 yrs[2]. They diagnose and treat acute and complicated diseases involving the brain, spinal cord, peripheral nerves, or muscles, with a particular emphasis on follow-up treatment. The discipline of child neurology encompasses diseases and disorders of the peripheral nervous system (PNS), autonomic nervous system (ANS), muscles, spinal cord, brain and blood vessels that affect individuals in these age groups. A pediatric 
Shaoli Sarker \& Mustafa Mahbub; Sch J App Med Sci, Jan, 2022; 10(1): 28-33

neurologist has the specialized training and knowledge to assess, diagnose, and treat the child if a child has problems that involve the nervous system. The conditions dealt with relatively simple disorders to diagnose such as migraines or cerebral palsy to more complex and rare conditions such as metabolic diseases or neurodegenerative disorders. Some examples of the types of conditions that can be encountered by specialists in this field include: genetic diseases of the nervous system, congenital metabolic abnormalities that affect the nervous system, congenital birth defects affecting the brain and spinal cord, such as spinal bifida, neurological developmental problems during childhood, childhood epilepsy, febrile seizures, movement disorders such as cerebral palsy, progressive neuromuscular conditions such as abnormal mental development, speech disabilities, muscular dystrophy and learning disabilities, autism spectrum disorders, behavioral disorders such as attention deficit hyperactivity disorder, headaches and migraine, hydrocephalus or excess fluid build-up in the brain, brain tumors, head injuries and their complications, palliative and hospice medicine, neuromuscular medicine, vascular neurology and intellectual disabilities \& sleep disorders. Neurosciences department might have several division like- cognitive neurology, autonomic disorders, pediatric neurology, epilepsy, general neurology, movement disorder, neurogenetics, neuro-epidemiology, neuro-oncology, vascular neurology, etc[3]. Several departments might have child patients who needs certain specialist care on neurological disorders who are referred by specialists of other disciplines to pediatrics neurology department for specified diagnosis \& proper treatment, since they excel in such cases. Therefore, recognizing that a child's brain differs greatly from an adult's brain, several tertiary care hospitals in Bangladesh have created a separate pediatric Neurology department [4]. According to Amanda M Yaworski et al., since referral wait times for pediatric neurological patients are at a rise, there is an increased burden on emergency department, and thus, rapid access clinics are necessary, since the clinics have high values and most of the patients come from OPD [5]. This shows that if the rate of referrals increases, then it is a wise decision to open up a clinic program for the cause. According to CHOC children's specialists, a few conditions might be best treated by a pediatric neurologist: Epilepsy and seizures, motor system disorders, headaches, development and behavioral disorders, neurogenetic and neurometabolic disorders, head injuries, brain tumors and malformations, hydrocephalus, complications of central nervous system infection, etc [6]. Pediatric neurologists combine competence in detecting and treating nervous system diseases like brain, spinal cord, muscles, nerves with knowledge of general medical illnesses in childhood and the particular requirements of the child and their family. Pediatric neurologists frequently collaborate with general pediatricians or other primary care physicians. Furthermore, pediatric neurologists may collaborate with other pediatric specialists to provide treatment for children who have more complicated or significant medical conditions.

\section{OBJECTIVES}

The objective of this study was to describe how patients, get referred to the specialists of pediatric neurosciences department, including frequency and reasons of the referrals.

\section{Materials \& Methodology}

We conducted this prospective study of recruiting 365 child patients who were referred to OPD of Pediatric Neurosciences Department in Dhaka Shishu Hospital. Ethical clearance was taken from concerned authority. During 10 consecutive medicine practice days, physicians and patients completed questionnaires for referred patients. Physicians also used medical records to complete the questionnaire properly. To obtain socio-demographic information, a semistructured questionnaire was employed. The study was made on children aged from newborn to 18 years old, who were referred from 3 specific departments of paediatric orthopedics, Paediatric ophthalmology \& paediatric neurosurgery to pediatric neurosciences department. The data were analyzed using simple proportion, rates and tables and was presented as frequency by using MS-Excel \& SPSS version 20.0.

\section{RESULTS}

During the research period, 365 children were referred to the pediatric department. Their referral pattern and features are shown in the tables and figures below. Table 1 shows the age distribution of children that has been referred to pediatric neurosciences department, where most of them $172(47.12 \%)$ were in 4-8 years of age. Then $101(27.67 \%)$ were in $8-12$ years, $59(16.16 \%)$ in $12-16$ and $33(9.04 \%)$ in $0-4$ years of age group respectively. As we could see from Table 1, the total number of children that were referred to the paediatric neurosciences department was 365 . Of them, $210(58 \%)$ were male children and $155(42 \%)$ were female children. The vast majority of the $288(78.9 \%)$ referred patients came from the general paediatric outpatient department. Among the remainder, $49(13.42 \%)$ were from paediatric orthopedic OPD, $13(3.56 \%)$ from ophthalmology OPD, $7(1.91 \%)$ from ophthalmology IPD, 7(1.91\%) from neurosurgery OPD and $1(0.3 \%)$ from neurosurgery IPD found in table-2. Where the total number of children under referral were $365,321(88 \%)$ needed diagnoses, where 44(12\%) didn't need any diagnosis, where all of them were referred from gynecology department. Among the referred patients, $321(88 \%)$ had neurological illness. On that patients, $88(24.11 \%)$ diagnosed as epilepsy, $64(17.53 \%)$ as autism spectrum disorder, $41(11.23 \%)$ as neuromuscular disease, $39(10.68 \%)$ as neurometabolic diaorder, $27(7.4 \%)$ as cerebral palsy, $30(8.22 \%)$ as 
Shaoli Sarker \& Mustafa Mahbub; Sch J App Med Sci, Jan, 2022; 10(1): 28-33 syndromic child due to genetic disorder, 17(4.66\%) as somatoform disorder, $13(3.56 \%)$ as constitutional speech delay, 2(0.55\%) diagnosed as peripheral neuropathy depicted in table- 3 .

Table-1: Age distribution of the referred children ( $N=365)$

\begin{tabular}{|l|l|l|l|}
\hline Age (in years) & n & \% & P Value \\
\hline $0-4$ yrs. & 33 & 9.04 & \multirow{2}{*}{0.001} \\
\hline $4-8$ yrs. & 172 & 47.12 & \\
\hline 8-12 yrs. & 101 & 27.67 & \\
\cline { 1 - 3 } $12-16$ yrs. & 59 & 16.16 & \\
\cline { 1 - 2 } Mean \pm SD & $8.56 \pm 3.66$ & \\
\hline
\end{tabular}

Chi-Square Test

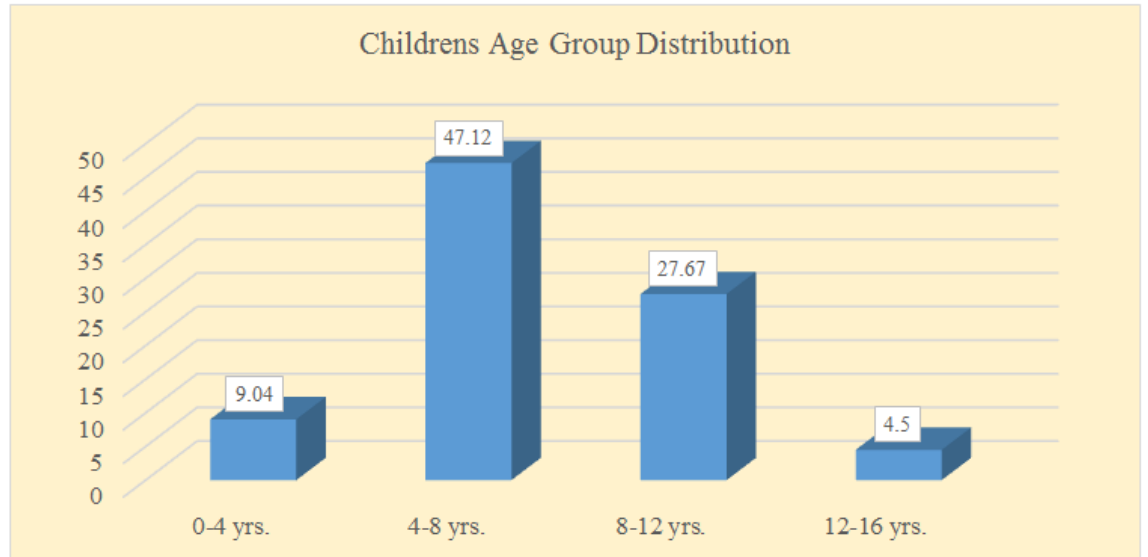

Fig-I: Age group distribution referred to pediatrics neurosurgery department $(\mathrm{N}=365)$

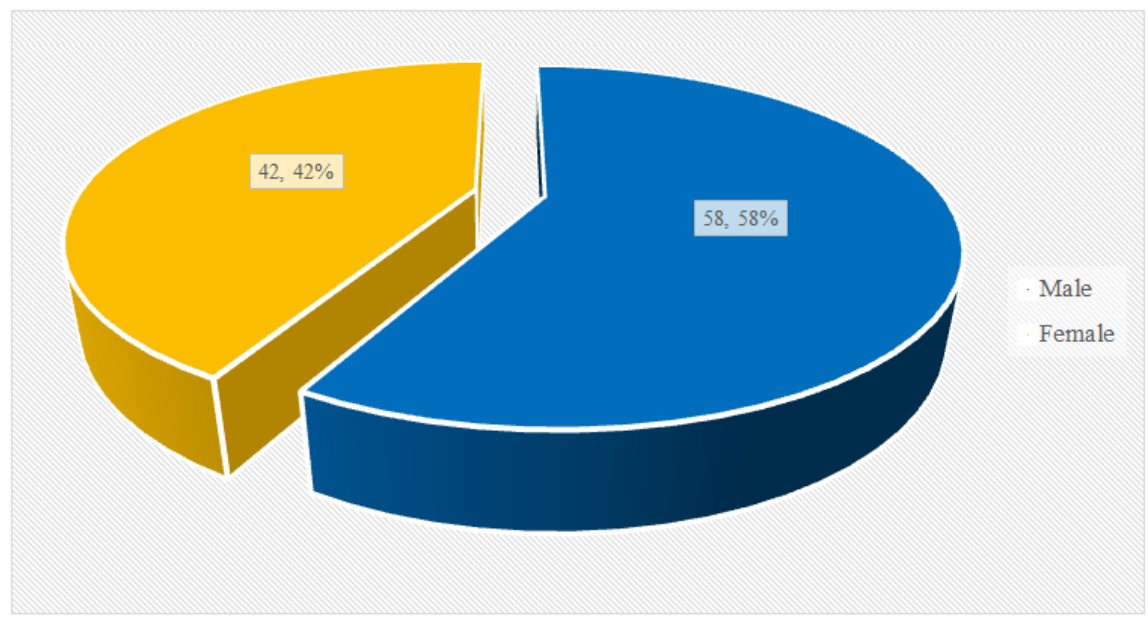

Fig-II: Percentage of male and female children referred to pediatrics neuroscience department $(\mathrm{N}=365)$

Table-2: Department-wise distribution of referred children $(\mathrm{N}=365)$

\begin{tabular}{|l|l|l|}
\hline Referred Department & n & \% \\
\hline General Paediatrics OPD & 288 & 78.9 \\
\hline Paediatric orthopedic OPD & 49 & 13.4 \\
\hline Ophthalmology OPD & 13 & 3.56 \\
\hline Ophthalmology IPD & 7 & 1.92 \\
\hline Neurosurgery OPD & 7 & 1.92 \\
\hline Neurosurgery IPD & 1 & 0.3 \\
\hline
\end{tabular}




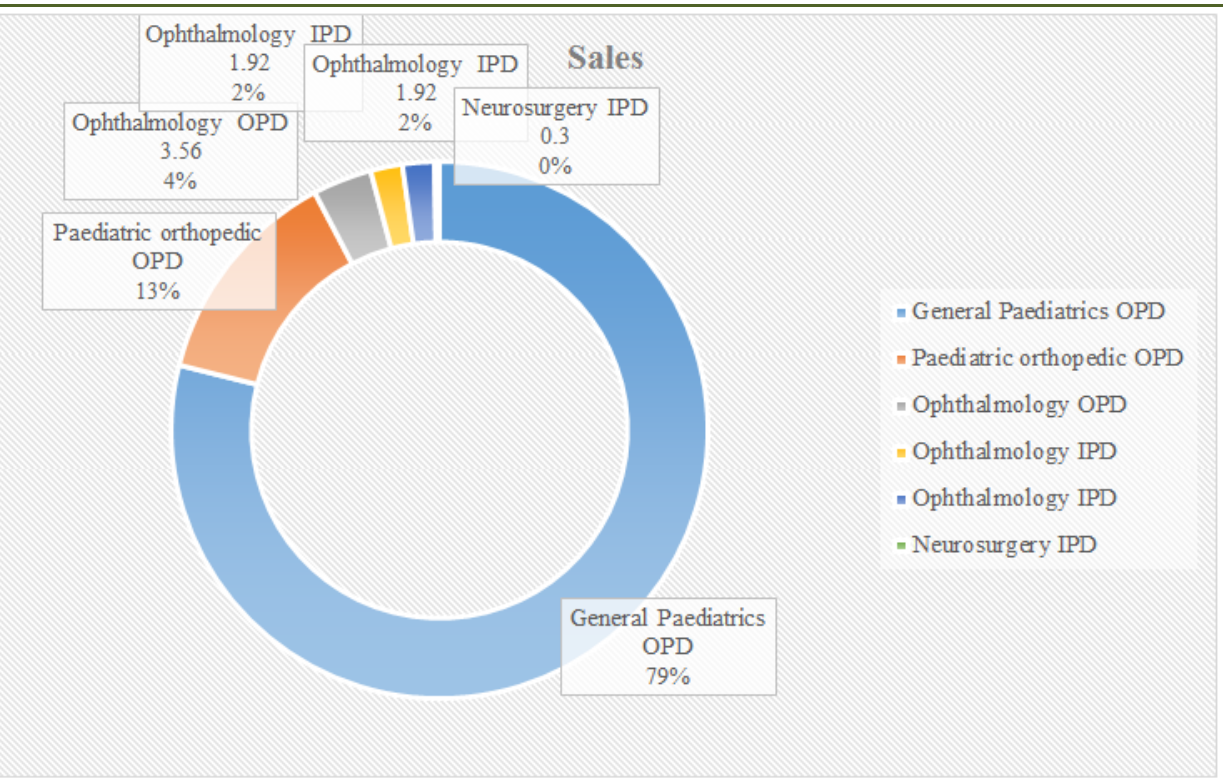

Fig-III: Patients referrals status to pediatrics neuroscience department $(\mathrm{N}=365)$

Table-3: Frequency of the diagnoses $(\mathrm{N}=365)$

\begin{tabular}{|l|l|l|}
\hline Diagnosis & $\mathbf{n}$ & $\mathbf{\%}$ \\
\hline Epilepsy & 88 & 24.11 \\
\hline Autism spectrum disorder & 64 & 17.53 \\
\hline Neuromuscular disease & 41 & 11.23 \\
\hline Neurometabolic disorder & 39 & 10.68 \\
\hline Syndromic child with ID & 30 & 8.22 \\
\hline Cerebral Palsy & 27 & 7.4 \\
\hline Somatoform disorder & 17 & 4.66 \\
\hline Constitutional speech delay & 13 & 3.56 \\
\hline Peripheral Neuropathy & 2 & 0.55 \\
\hline
\end{tabular}

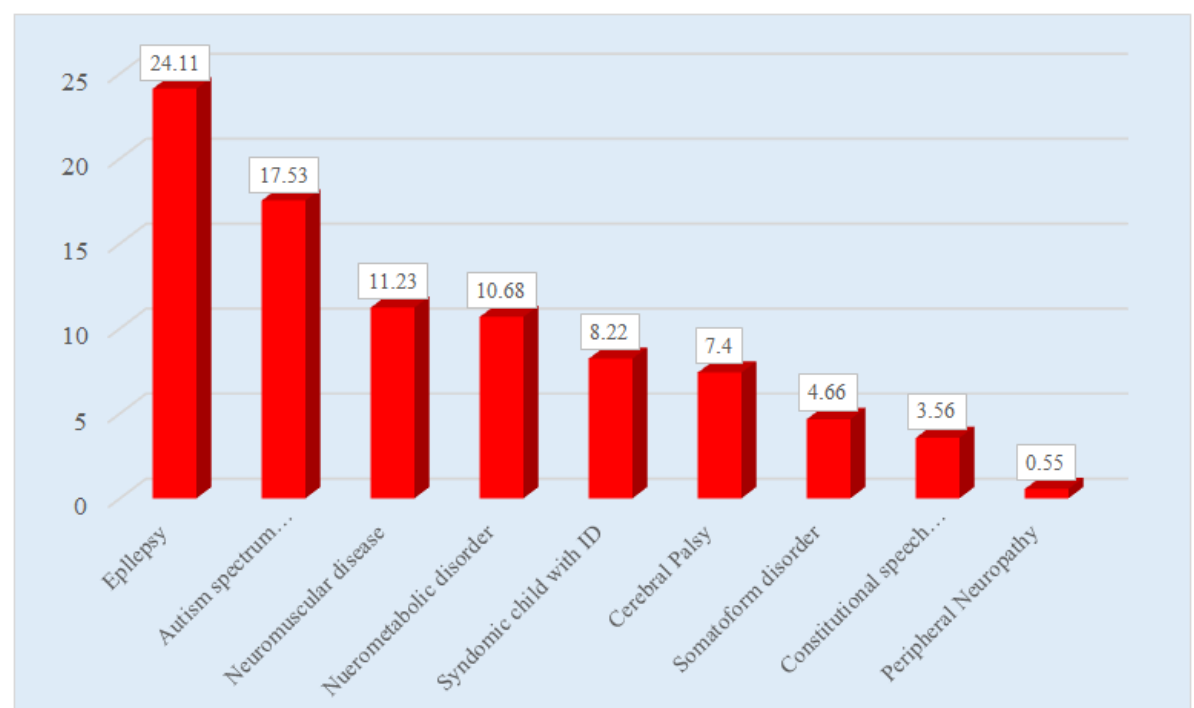

Fig-III: Patients referrals status to pediatrics neuroscience department $(\mathrm{N}=365)$

\section{DiSCUSSION}

This prospective study was conducted at the Pediatric Neurosciences Department in Dhaka Shishu Hospital to examine the referral pattern and to make understand the neurological diagnosis of referred patients. The age distribution revealed that the majority of the $172(47.12 \%)$ of the referred patients were between the ages of 4 and 8 years. MM Jalal Uddin $e t$ al. observed similar findings in research from Bangladesh's National Institute of Neurosciences and Hospital addressing the psychiatric department [1]. 
Among the responders, 210(58\%) were male, while the remaining $155(42 \%)$ were female. A similar study by Alejandro Rodriguez was to seek the referral patterns of Uveitis in a tertiary eye care center portrays the opposite, by recording the male to female ratio- 1:1.4 at 1996 [9]. Shaikh et al. [10] in a rural medical college hospital in Bangladesh where $62 \%$ of female and rest were male patients who were referred to psychiatry department and this may be due to that female present their problem through somatic complaints. This can mean that the male children, at least in Bangladesh, have a higher risk of getting neurological problem symptoms than the female children. Because some patients were unaware of their symptoms, they were initially sent to a neurologist, a gynecologist, or a neurosurgeon. Among the referred patients, 288(78.9\%) referred patients came from the general paediatric OPD. Among the remainder, 49(13.42\%) were from paediatric orthopedic OPD, 13(3.56\%) from ophthalmology OPD, 7(1.91\%) from ophthalmology IPD, $7(1.91 \%)$ from neurosurgery OPD and $1(0.3 \%)$ from neurosurgery IPD. In this study, it was found out that most of the patients $288(78.9 \%)$ were referred from general paediatric OPD and only a few $1(0.3 \%)$ were referred from neurosurgery IPD. Generally, when the patients go to a department, and if the specialists can't determine the perfect and suitable diagnosis, then he/she refer the patients to the other department. Among the OPD referral most $448(93.92 \%)$ of the patients were referred from neurology department, $18(3.77 \%)$ patients were referred from paediatric neurology department and only $3(0.63 \%)$ patients were referred from neurosurgery department. ${ }^{1}$ In a study in Europe by Jonge et al. found $1.8 \%$ of IPD was referred to consultation liaison psychiatry which is consistent in our study[11]. Malnutrition and micronutrient deficiencies continue to impede millions of children's cognitive and physical development in Bangladesh. Stunting is reported to be $54 \%$ among children under the age of five among the lowest groups [12]. In this study patients diagnosed as, 88(24.11\%) Epilepsy, 64(17.53\%) Autism spectrum disorder, 41(11.23\%) Neuromuscular disorder, 39(10.68\%) Neurometabolic disorder, 27(7.4\%) Cerebral palsy, 30(8.22\%) Syndromic child with ID, 17(4.66\%) Somatoform disorder, $13(3.56 \%)$ Constitutional speech delay \& finally $2(0.55 \%)$ Peripheral neuropathy. A study conducted by Shaikh et al. [9] in a rural tertiary care medical college hospital in Bangladesh found $16.3 \%$ of somatoform disorders in their study. Carson et al. [12] found $20 \%$ of anxiety disorders in their study in neurology OPD. Ahmed et al. [13] found $3.66 \%$ of psychosis and $3 \%$ of BMD in their study. Unawareness is significant while people try to seek treatment, and for this reason, people do not tend to go to the specialists who can actually treat them. That being said, people do not specialize in understanding a disease and make diagnosis out of the symptoms. For this reason, the number of referrals in a hospital is far huger than one can expect. Interdepartmental collaboration is required to provide patients with complete care. It is especially vital to increase awareness of children's neurological issues. To have additional data in this respect, more broad-based research, such as an assessment of pediatric neurology among children attending neurosciences departments in hospitals, is necessary. However, the referral process is a very excellent approach to direct the route for patients seeking treatment; otherwise, people are not always knowledgeable enough to comprehend where they should go for their condition and with whom they should speak.

\section{Limitations OF STUDY}

As this study was a prospective study there were some limitations also, missing few of the records, proper evaluation of socio-demographic picture was difficult because of record keeping system was not up to the mark. As well as a single center study with short study duration and small sample size added to the limitations.

\section{CONCLUSION}

This research represents several parties' existing referral practices. The most common cause for referral is to seek advice from a specialist. For the majority of their referred patients, a specialist from a department wants a collaborative connection with specialists of other departments. Physicians who get clinical competency training may be most beneficial for referred conditions. Education on the referral process should emphasize the referring physicians and specialists distinct roles, particularly as they relate to effective ways of coma aging referred patients.

\section{REFERENCE}

1. Uddin, M. J., Chowdhury, M. J. H., Islam, M. J., Chowdhury, T. I., Baqui, M., Sarker, P. K., ... \& Mohammad, Q. D. (2015). Referral Pattern of Patients to Psychiatry Department at Neuroscience Institute in Bangladesh. Journal of National Institute of Neurosciences Bangladesh, 1(1), 8-11.

2. Paediatric neorology. North Babylon, New York: (631) 462-1184.

3. Pandolfo, M., Blecic, S., Mavroudakis, N., Van Bogaert, P., Paquier, P., Manto, M., \& Zegers de Beyl, D. (2002). The neurology department. Revue medicale de Bruxelles, 23, 127-130.

4. Allen, L., Kelly, B. B., \& National Research Council. (2015). Child development and early learning. In Transforming the Workforce for Children Birth through Age 8: A Unifying Foundation. National Academies Press (US).

5. Yaworski, A. M., Yager, J. Y., Richer, L., Mailo, J., Rajapakse, T., \& Kassiri, J. (2021). Improved care and management of paediatric neurological patients evaluated at a paediatric Rapid Access 
Shaoli Sarker \& Mustafa Mahbub; Sch J App Med Sci, Jan, 2022; 10(1): 28-33

Neurology clinic: A pilot study. Journal of Paediatrics and Child Health, 57(6), 908-912.

6. Herman, S. T. (2002). Epilepsy after brain insult: targeting epileptogenesis. Neurology, 59(9 suppl 5), S21-S26.

7. Rodriguez, A., Calonge, M., Pedroza-Seres, M., Akova, Y. A., Messmer, E. M., D'Amico, D. J., \& Foster, C. S. (1996). Referral patterns of uveitis in a tertiary eye care center. Archives of ophthalmology, 114(5), 593-599.

8. Shaikh, M. A. K., Ali, M. Z., Islam, M. S., \& Mokhlesuzzaman, A. K. M. (2011). Study of referral pattern for psychiatric evaluation in psychiatric OPD in a rural tertiary care hospital. KYAMC Journal, 2(1), 128-131.

9. de Jonge, P., Huyse, F. J., Herzog, T., Lobo, A., Malt, U., Opmeer, B. C., ... \& Krabbendam, A. (2001). Referral pattern of neurological patients to psychiatric Consultation-Liaison Services in 33 European hospitals. General hospital psychiatry, 23(3), 152-157.

10. Sultana, P., Rahman, M., \& Akter, J. (2019). Correlates of stunting among under-five children in Bangladesh: a multilevel approach. $B M C$ nutrition, 5(1), 1-12.

11. Carsson, A., Rinbauer, B., Mac Kanzie, W. C., \& Sharpe, M. (2000). Neurological diseases, Emotional disorders and disability: they are related: a study of 300 consecutive new referral to a neurological patient department. $J$ Neurol Neurosurg Psychiatry, 68(2), 202-206.

12. Ahmad, J., Shoib, S., \& Dar, M. M. (2013). Psychiatry morbidity in patients attending neurological Outpatient department. Int J Med Sci Public Health, 2, 951-953. 